\title{
The 2019 JHG Young Scientist Award
}

\section{Naomichi Matsumoto ${ }^{1}$}

Received: 4 December 2019 / Accepted: 4 December 2019 / Published online: 19 December 2019

(c) The Author(s), under exclusive licence to The Japan Society of Human Genetics 2020

The JHG Young Scientist Award recognizes articles that have made a significant contribution to the Journal of Human Genetics, thanks to their scientific excellence and impact in the field of human genetics.

We are pleased to announce the winners of the 2019 JHG Young Scientist Award.

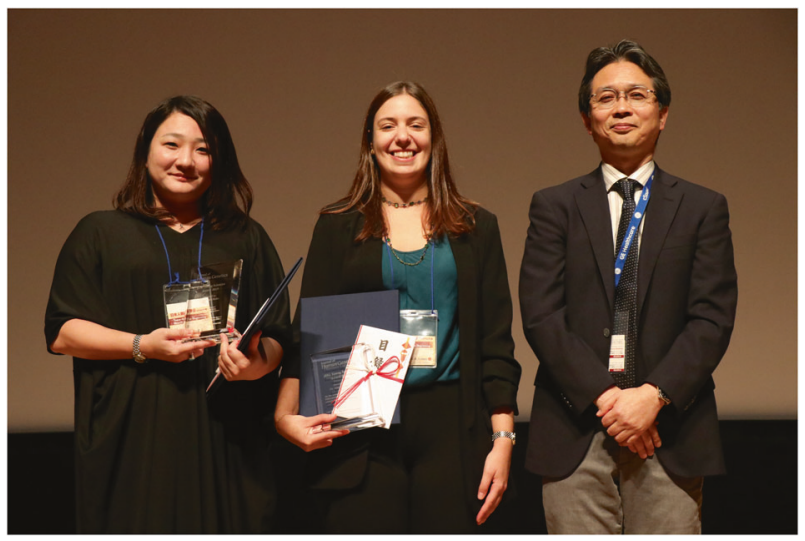

Ana S.A. Cohen

Present affiliation: Department of Genetics and Genomic Sciences, Icahn School of Medicine at Mount Sinai, New York, NY, USA.
Previous affiliation (associated with the work awarded): Department of Medical Genetics, British Columbia Children's Hospital Research Institute, University of British Columbia, Vancouver, BC, Canada.

For the paper entitled

$E E D$-associated overgrowth in a second male patient.

J Hum Genet (2016) 61, Issue 9 Page 831-834, https://doi.org/10.1038/jhg.2016.51.

\section{Mariko Okubo}

Department of Neuromuscular Research, National Institute of Neuroscience, NCNP.

For the paper entitled

Genetic diagnosis of Duchenne/Becker muscular dystrophy using next-generation sequencing: validation analysis of $D M D$ mutations.

J Hum Genet (2016) 61, Issue 6 Page 483-489, https://doi.org/10.1038/jhg.2016.7.

We would like to offer our warmest congratulations and wish them every success in their future careers.

Naomichi Matsumoto

Editor-in-Chief

Journal of Human Genetics

Naomichi Matsumoto

naomat@yokohama-cu.ac.jp

1 Department of Human Genetics, Yokohama City University Graduate School of Medicine, Yokohama, Japan 